\section{Treatment of Intrabony Defects with Anorganic Bone Matrix/P-15 or Guided Tissue Regeneration in Patients with Aggressive Periodontitis}

\author{
Adriana C. Queiroz ${ }^{1}$, Priscila Brasil da Nóbrega ${ }^{2}$, Fabiola S. Oliveira ${ }^{2}$, Arthur \\ B. Novaes Jr. ${ }^{2}$, Mário Taba Jr. ${ }^{2}$, Daniela B. Palioto ${ }^{2}$, Márcio F. M. Grisi ${ }^{2}$, Sergio \\ L. S. Souza²
}

'Dental School, UFAM - Federal University of Amazonas,

Manaus, AM, Brazil

${ }^{2}$ Department of Surgery, Oral and Maxillofacial Traumatology and Periodontology, Dental School of Ribeirão Preto, USP - University of São Paulo, Ribeirão Preto, SP, Brazil

Correspondence: Prof. Dr. Sérgio Luis Scombatti de Souza, Avenida do Café, s/n, 14040-904 Ribeirão Preto, SP, Brasil. Tel. +55-16-36024141. e-mail: scombati@forp.usp.br

\begin{abstract}
Intrabony periodontal defects present a particular treatment problem, especially in patients with generalized aggressive periodontitis (G-AgP). Regenerative procedures have been indicated for this clinical situation. The aim of this study was to compare treatment outcomes of intrabony periodontal defects with either anorganic bone matrix/ cell binding peptide (ABM/P-15) or guided tissue regeneration (GTR) in patients with $\mathrm{G}-\mathrm{AgP}$. Fifteen patients, with two intrabony defects $\geq 3 \mathrm{~mm}$ deep, were selected. Patients were randomly allocated to be treated with ABM/P-15 or GTR. At baseline and at 3 and 6 months after surgery, clinical and radiographic parameters and IL- $1 \beta$ and IL- 6 gingival fluid concentrations were recorded. There was a significant probing pocket depth reduction $(p<0.001)$ for both groups $(2.27 \pm 0.96 \mathrm{~mm}$ for ABM/P-15 group and $2.57 \pm 1.06 \mathrm{~mm}$ for GTR group). Clinical attachment level gain ( $1.87 \pm 0.94 \mathrm{~mm}$ for ABM/P-15 group and $2.09 \pm 0.88 \mathrm{~mm}$ for GTR group) was also observed. There were no statistically significant differences in clinical parameters between the groups. The radiographic bone fill was more expressive in ABM/P-15 group $(2.49 \mathrm{~mm})$ than in GTR group $(0.73 \mathrm{~mm})$. In subtraction radiographs, the areas representing gain in density were $93.16 \%$ of the baseline defect for ABM/P-15 group versus $62.03 \%$ in GRT group. There were no statistically significant differences in inter-group and intra-group comparisons with regards to IL-1 $\beta$ and IL-6 quantification. Treatment of intrabony periodontal defects in patients with $\mathrm{G}-\mathrm{AgP}$ with ABM/P-15 and GTR improved significantly the clinical outcomes. The use of ABM/P-15 promoted a better radiographic bone fill.
\end{abstract}

\author{
Key Words: periodontal \\ regeneration, periodontal \\ surgery, aggressive periodontitis, \\ biomaterial, bone graft, \\ guided tissue regeneration.
}

\section{Introduction}

Aggressive periodontitis (AgP) affects a minority of periodontal patients but it is highly significant since it is characterized by severe destruction of the supporting structure of the teeth. In general, $\mathrm{AgP}$ can occur at any age and is frequently characterized by a clinical manifestation at an early age, which indicates that the etiologic agents are able to cause clinically detectable levels of the disease within a relatively short time (1). Because of its less common occurrence, few studies have evaluated different treatment protocols for this condition. Almost all therapeutic procedures are aimed at stopping the inflammatory process and suppressing the growth of pathogenic bacteria. The treatment of the infection should be the most important goal of periodontal therapy in patients with AgP. However, once the periodontal lesions have occurred, the aim of therapy should be the attempt to restore the tissues destroyed by periodontal disease (2).

The complete and predictable regeneration of the periodontium remains a critical goal in the periodontal treatment. Although periodontal regeneration is a possible objective in several procedures, such as guided tissue regeneration (GTR), grafting with biomaterials and application of biological agents, outcomes of such treatments are not always predictable (3). This variability has been attributed to many factors, such as patient characteristics, variations in anatomy defect and design of the surgical approach (4).

The principle of GTR is based on the use of membranes that delays the apical migration of the gingival epithelium, allowing granulation tissue derived from the periodontal ligament and bone tissues to repopulate the space adjacent to the denuded root surface (5). One of the most used membranes for GTR is the expanded polytetrafluoroethylene (ePTFE) membrane. In this context, the titanium-reinforced membrane is a modification of the ePTFE membrane, which enhances its ability to maintain the space for regeneration and to support the gingival tissues.

Another way to address periodontal regeneration is using bone replacement grafts. A wide range of graft materials have been applied and evaluated, showing good clinical results. The main limitation associated with the use of bone grafts in periodontal regeneration is that, despite the fact they play a positive role in bone growth, they do 
not predictably control the cellular events in the healing of periodontal wound which lead to new attachment formation. In order to develop biologic modalities that may enhance wound healing, some investigators have focused on the cell-binding aspect. A cell-binding domain of type I collagen has been identified, and it has been shown that a synthetic 15-residue peptide (P-15), analogous to the domain of collagen, binds cells with high affinity. Incorporation of these peptides into the microstructure of anorganic bone grafting material (ABM) can be expected to emulate the properties of collagen in promoting cell attachment, migration, and differentiation (6). In humans, clinical studies have demonstrated that ABM/P-15 showed significantly higher bone defects fill when compared with defects treated with demineralized freeze-dried bone allograft (DFDBA), open flap debridement (DEBR) and ABM (7-9). $A B M / P-15$ has also been applied to ridge preservation and to treat isolated gingival recession defects $(10,11)$.

The traditional methods of monitoring periodontal treatment outcomes are clinical and radiographic parameters. However, advances in periodontal diagnosis are moving toward methods whereby periodontal activity can be identified and quantified by measuring biomarkers found in gingival crevicular fluid (GCF), serum and saliva. Among these biomarkers, interleukin-1 (IL-1) and interleukin-6 (IL-6) have been investigated in many studies $(12,13)$, mainly evaluating the levels in healthy and diseased sites.

Patients with AgP usually have residual vertical bone defects as a result of periodontal disease and regenerative procedures are one of the possible treatment options. The objective of this 6-month randomized controlled clinical trial was to evaluate the response of ABM/P-15 compared with GTR procedures in the treatment of periodontal defects in patients with Generalized AgP (G-AgP).

\section{Material and Methods}

\section{Subject Selection and Clinical Procedures}

The study included subjects with all of the following criteria: (i) G-AgP; (ii) at least 20 teeth present; (iii) good general health and (iv) aged 16 to 35 years. Subjects were excluded from the study if they: (i) were considered to have a diagnosis of chronic periodontitis; (ii) were pregnant or lactating females; (iii) suffered from any other systemic disease; (iv) were taking long-term anti-inflammatory drugs; (v) had received periodontal treatment within the last 6 months; (vi) were allergic to penicillin or metronidazole. Informed consent was obtained from all the subjects to be enrolled in the study and the protocol was approved by the Institution's Human Research Committee (protocol \#2006.1.964.58.9).

Fifteen patients whose treatment plan included reconstructive periodontal surgical procedures to treat bilateral intrabony periodontal defects were selected for the study. A split-mouth design was adopted and, therefore, $\mathrm{n}=15$ for both groups (ABM/P-15 and GTR). All patients completed a plaque control program. In sequence, full-mouth scaling and root planning were performed with Gracey periodontal curettes (Hu-Friedy Instruments, Chicago, IL, USA) and ultrasonic instrumentation (Cavitron Select; Dentsply Cavitron, Long Island, NY, USA.) All patients received systemic antibiotics (amoxicillin, $500 \mathrm{mg}$, three times a day and metronidazole, $400 \mathrm{mg}$, twice a day for 10 days) starting 24 $\mathrm{h}$ before the full-mouth scaling and root planning (1). Plaque control and oral hygiene instruction were performed weekly. The period between initial therapy and the regenerative procedures was defined individually, according to each patient. The first reevaluation was performed 45 days after the nonsurgical periodontal therapy. From then on, an individual treatment plan was defined for each patient and additional scaling and root planning, dental extractions and open flap debridement surgeries were provided throughout the mouth, if required. The regenerative procedures were scheduled only when all the necessary procedures were performed and the patients had achieved levels of at least $20 \%$ on plaque and gingival index. Before the surgeries, baseline documentation was obtained. Two bilateral intrabony periodontal defects in the same arch (not necessarily in the same teeth), with an approximate depth of $3 \mathrm{~mm}(7,8)$, as previously measured on radiographies and confirmed during surgeries, were selected. The periodontal measurements were performed by a single blinded experienced examiner, who was not involved with the surgical procedures and recorded at six sites per tooth. The clinical measurements included gingival recession (GR); probing pocket depth (PPD) and relative clinical attachment level ( $\mathrm{rCAL}$ ), measured as the distance from a fixed point in a stent to the bottom of the pocket. An automated periodontal probe (Florida Probe Corporation, Gainesville, FL, USA.) and an acrylic stent with reference marks were used to determine the same measurement site at baseline and 6 months after surgery.

\section{Radiographic Procedures}

Standardized radiographs were obtained at baseline and at 3 and 6 months after periodontal surgery (Fig. 1). The radiographs were taken with the paralleling technique employing an x-ray unit and a digital sensor (RVG Trophy; Eastman Kodak Company, Rochester, NY, USA.) The images were $768 \times 512$ pixels and had a 256 grays scale. Exposure time was set at $0.25 \mathrm{~s}$. In order to standardize the geometry, a modification of holders (XCP; Rinn Corporation, Elgin, IL, USA) connected to an individual silicone bite-block with occlusal registration was used. Using Image Tool software for Windows, version 3.00 (UTHSCSA, San Antonio, TX, USA), the following linear distances were measured in 
millimeters: distance from the radiographic cementenamel junction ( $r \mathrm{CEJ})$ to the base of the defect $(\mathrm{rBD})$ and distance from the rCEJ to the radiographic alveolar crest (rAC). Where an interproximal restoration was present, its most apical extension was used instead of the rCEJ. The differences between the 6-month and baseline values for
rCEJ-rBD indicated the amount of radiographic bone fill (rBF) within the defect. The differences between rCEJ-rAC recorded at baseline and at 6 months were identified as the amount of radiographic crestal bone resorption ( $r C B R)$. The radiographic density values were obtained by the mean gray value of the pixels using histogram command.
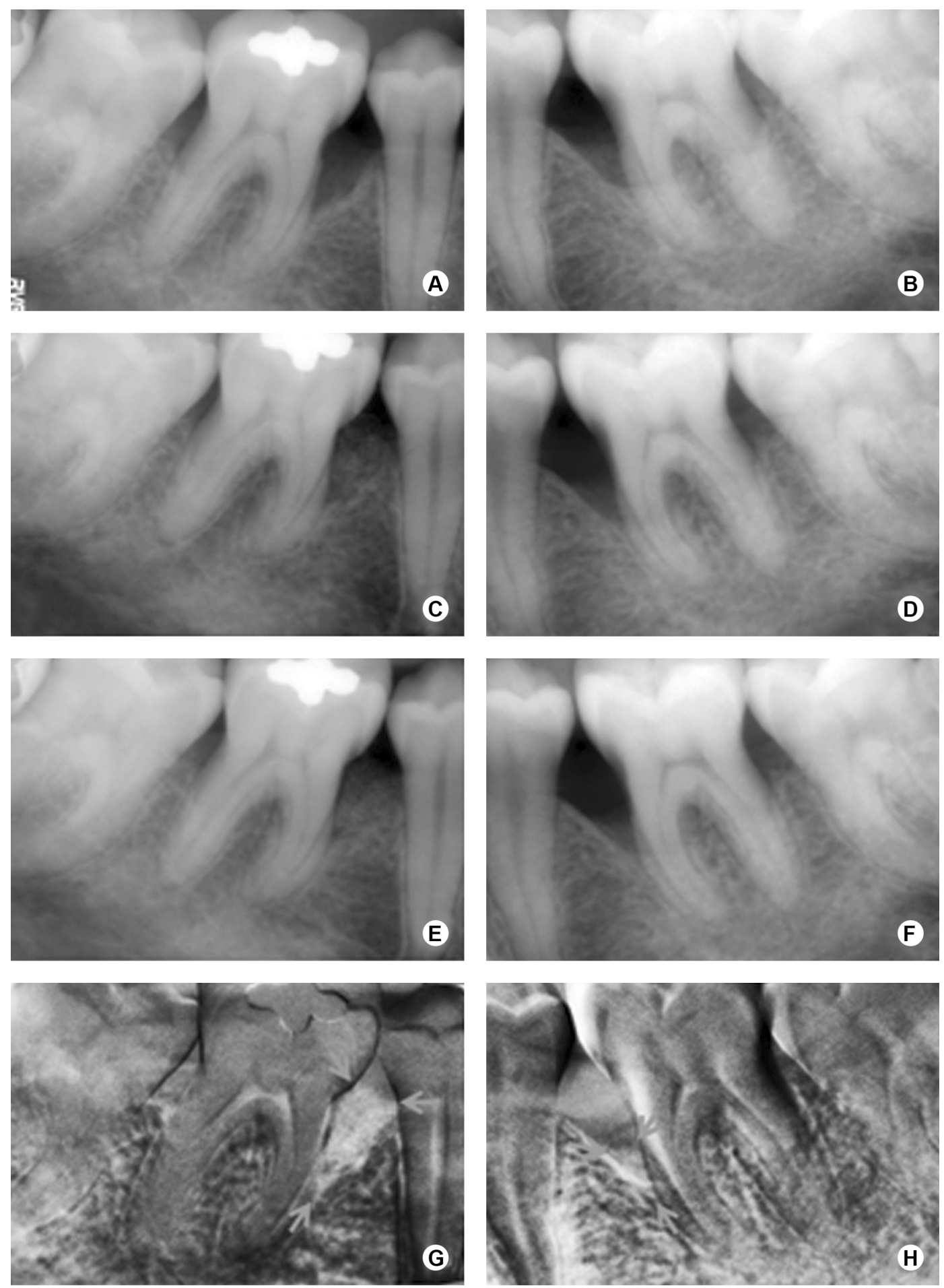

Figure 1. A,B: Baseline radiographs; C: 3-month radiograph in ABM/P-15 group; D: 3-month radiograph in GTR group; E: 6-month radiograph in ABM/P-15 group; F: 6-month radiograph in GTR group; G: Subtraction radiograph in ABM/P-15 group, with a brighter area showing the region with gain in density (arrows); H: Subtraction radiograph in GTR group, with a brighter area showing the region with gain in density (arrows). 
Standardized regions of interest (ROIs), which corresponded to 16 square pixels, were defined for each defect. The ROls were not superimposed on any portion of the tooth surface and all attempts were made to confine the square completely within the defect. Four ROls were selected for each defect. The first ROI was placed in the most apical portion of the defect that could be visualized. The second ROI was placed approximately halfway between the base of the defect and the alveolar crest. The third ROI was placed just below the alveolar crest in the lateral aspect of the defect. The fourth ROI was used as a control region and was placed at a distant, untreated site; this ROI was not expected to demonstrate changes in radiographic density during the study. Digital subtraction radiographs (DSR) were obtained using the Emago Dental Software (Oral Diagnostics Dental Systems, Amsterdam, The Netherlands). The pairs of radiographs had the gray level calibrated and an alignment of images was performed to correct small geometric misalignments. The areas that showed gain in radiographic density (lightened areas) where measured $\left(\mathrm{mm}^{2}\right)$. In order to compare these areas with the baseline defects, the areas of the initial defects were measured in the conventional baseline radiographs. The percentage of areas with gain in radiographic density observed in DSR in relation to the baseline defects was calculated.

\section{GCF Sampling Method}

GCF was sampled from the sites to be treated at baseline and 3 and 6 months after the surgery. Briefly, teeth were air-dried and isolated with cotton rolls, supragingival biofilm was removed and paper strips (Periopaper; Oraflow Inc., Plainview, NY, USA.) were placed in the sulcus for 30 s. Twelve paper strips were collected per site and strips contaminated by blood and/or saliva were discarded. Periotron 6000 (Oraflow Inc.) was used to determine the amount of GCF. A standard curve correlating digital readout to volume was constructed and the readings from the Periotron 6000 obtained in each sample were converted to actual volume $(\mu \mathrm{L})$ by reference to the standard curve, applying a fourth-order polynomial regression. The paper strips were stored at $-80^{\circ} \mathrm{C}$ until the assays.

\section{Surgical Procedures}

The surgical procedures are represented in Figure 2. After administration of local anesthesia, full-thickness flaps were elevated to provide access to all the surfaces of the defects. Sulcular incisions were made through the bottom of the crevice extending to the mesial and distal adjacent teeth, including all the papilla on the flap. No releasing incision was performed. Granulomatous tissue was carefully removed, and root planning was performed. EDTA at 24\%, neutral pH, in 3\% carbopol gel, was applied for $2 \mathrm{~min}$, followed by abundant sterile saline irrigation and continuous aspiration. Randomly, by a coin toss, one defect was treated with ABM/P-15 (PepGen P-15 ${ }^{\circledR}$; Dentsply Friadent CeraMed, Lakewood, CO, USA.) (ABM/P-15 group) and the other one with GTR (GTR group) in the same surgical procedure. ABM/P-15 was placed into the defects up to the adjacent crestal walls, soaked with sterile saline. In the GTR group, an interproximal titanium reinforced non-absorbable ePTFE membrane (TRI1/TRI2; Gore-Tex Regenerative Material, W.L. Gore \& Associates Inc., Flagstaff, AZ, USA) was adjusted to obtain precise adaptation to the interdental portion of the teeth. Afterwards, the membrane was positioned at the level of, or coronal to, the bone crest to completely cover the defects, overlapping at least $3 \mathrm{~mm}$ of the residual bone (2) and sutured with e-PTFE sutures. Wound closure was obtained by repositioning the flaps coronally, if required. The flaps were also sutured with e-PTFE sutures. Patients were instructed to rinse two times a day with a $0.12 \%$ chlorhexidine digluconate solution for one month postoperatively, and amoxicillin $500 \mathrm{mg} /$ clavulanate potassium $125 \mathrm{mg}$, three times a day, was prescribed for 10 days. A non-steroidal antiinflammatory drug (Nimesulide $100 \mathrm{mg}$ ) was also prescribed twice a day, for 5 days. Weekly postoperative prophylaxes were done during the first month and monthly from then on. In cases of membrane exposure, Doxycycline $100 \mathrm{mg}$ was prescribed every $12 \mathrm{~h}$ in the first day and once a day until the membrane removal, and the patients were instructed to carefully clean the surgical sites with a cotton swab soaked in $0.12 \%$ chlorhexidine digluconate solution two times a day. Four weeks after surgery, patients treated with ePTFE membranes underwent a second surgery in order to carefully remove it. The same surgical protocol was used to gain access to the membrane.

\section{Cytokine Quantification}

On the day of the analysis, the strips of each site were eluted in $600 \mu \mathrm{L}$ phosphate buffered saline (PBS) containing $0.1 \%$ Tween 20 (USB Corp., Cleveland, OH, USA) and $1 \mu \mathrm{L}$ of protease inhibitor cocktail (Sigma-Aldrich Inc., St. Louis, MO, USA). The tubes were shaken for $30 \mathrm{~min}$ and centrifuged at 10,000 rpm for $5 \mathrm{~min}$. The supernatant was divided into aliquots for the determination of each biochemical compound. The presence of cytokines in the gingival crevicular fluid samples was determined using commercial enzyme-linked immunosorbent assay kits (Human Quantikine HS IL-1 $\beta / I L-6$, ELISA kit, HSLB00C/HS600B; RED Systems, Minneapolis, MN, USA), according to the manufacturer's instructions. Briefly, samples and standards were added to the wells of the microplate, pre-coated with capture antibody. Any analyte present was bound by the immobilized 

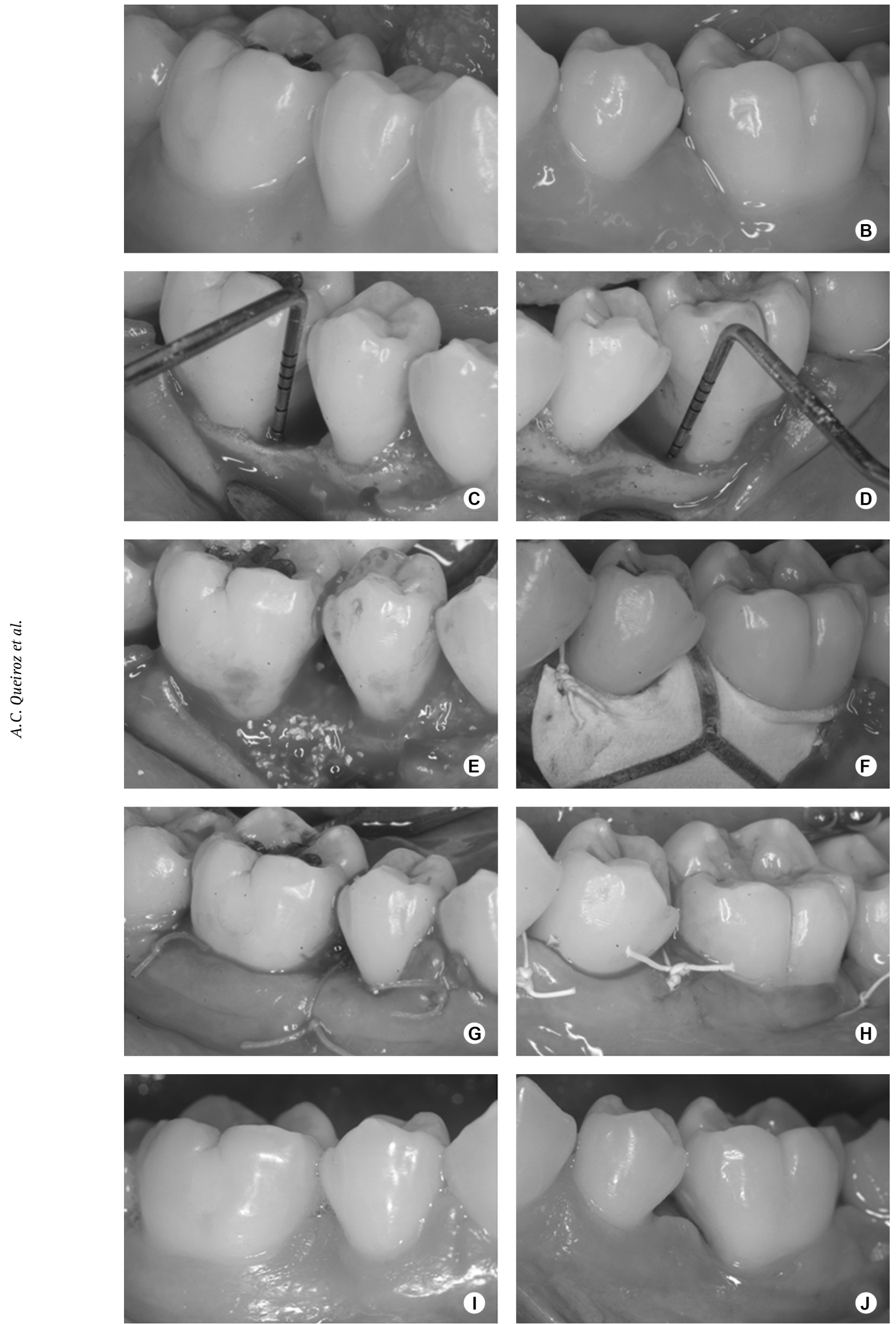

Figure 2. A,B: Baseline view; C, D: Intrabony defects; E: ABM/P-15 in place; F: Membrane positioned and sutured. G,H: Wound closure sutures. I, J: 6-month view. 
antibody. After an incubation period, unbound materials were washed away. The detection antibody was added and bound to the captured analyte. Unbound detection antibody was washed away. NADPH substrate solution was added and a color developed. Amplifier solution was added and the color deepened proportionally on the amount of analyte present in the sample. Stop solutions were added and the absorbance of the color at $490 \mathrm{~nm}$ was measured. Concentrations of the cytokines were determined by generating a standard curve for comparison. Concentrations of cytokines were corrected for GCF volume and were defined as $\mathrm{pg} / \mu \mathrm{L}$.

\section{Statistical Analysis}

Data were recorded as mean \pm standard deviation for clinical and radiographic parameters and mean \pm standard error of the mean for cytokine quantification. The patient was the experimental unit $(n=15)$. Considering

Table 1. Clinical and radiographic parameters at baseline and 6 months after surgery

\begin{tabular}{|c|c|c|c|c|}
\hline Parameter* & Baseline & 6 months & $p$ value & Change \\
\hline PPD (mm) & & & & PPD reduction \\
\hline ABM/P-15 & $5.36 \pm 1.28$ & $3.09 \pm 0.84$ & $<0.001 \dagger$ & $2.27 \pm 0.96$ \\
\hline GTR & $5.41 \pm 1.23$ & $2.85 \pm 0.50$ & $<0.001+$ & $2.57 \pm 1.06$ \\
\hline$p$ value & 1.00 & 0.476 & & 0.408 \\
\hline CAL (mm) & & & & CAL gain \\
\hline ABM/P-15 & $10.31 \pm 1.29$ & $8.45 \pm 1.18$ & $<0.001+$ & $1.87 \pm 0.94$ \\
\hline GTR & $11.15 \pm 1.28$ & $9.05 \pm 1.43$ & $<0.001 \dagger$ & $2.09 \pm 0.88$ \\
\hline$p$ value & 0.057 & 0.099 & & 0.495 \\
\hline GR (mm) & & & & GR increase \\
\hline $\mathrm{ABM} / \mathrm{P}-15$ & $0.27 \pm 0.44$ & $0.86 \pm 0.54$ & $<0.001 \dagger$ & $0.58 \pm 0.29$ \\
\hline GTR & $0.29 \pm 0.48$ & $0.92 \pm 0.71$ & $<0.001 \dagger$ & $0.64 \pm 0.47$ \\
\hline$p$ value & 1.00 & 0.910 & & 0.629 \\
\hline rCEJ-rAC (mm) & & & & $\mathrm{rCBR}$ \\
\hline ABM/P-15 & $2.82 \pm 1.21$ & $3.14 \pm 1.63$ & 0.278 & $-0.32 \pm 1.05$ \\
\hline GTR & $3.57 \pm 1.10$ & $4.24 \pm 1.08$ & 0.064 & $-0.67 \pm 1.05$ \\
\hline$p$ value & 0.278 & 0.221 & & 0.382 \\
\hline rCEJ-rBD (mm) & & & & $\mathrm{rBF}$ \\
\hline ABM/P-15 & $6.07 \pm 1.72$ & $3.58 \pm 1.45$ & $0.002 t$ & $2.49 \pm 1.88$ \\
\hline GTR & $6.22 \pm 1.59$ & $5.48 \pm 1.02$ & 0.172 & $0.73 \pm 1.21$ \\
\hline$p$ value & 0.599 & $0.001^{*}$ & & $0.002 t$ \\
\hline
\end{tabular}

PPD: probing pocket depth; CAL: clinical attachment level; GR: gingival recession; rCEJ-rAC: distance from cementoenamel junction to alveolar crest; rCEJ-rBD: distance from cementoenamel junction to radiographic base of the defect. Wilcoxon signed-rank test. *mean \pm sd. + Statistically significant difference $(p<0.05)$. the normality of the data distribution and as it was a splitmouth design study, non-parametric paired tests were used. Statistical analysis was accomplished utilizing the Wilcoxon signed-rank test and Friedman test with Dunn's post-test, with significance set at the 0.05 level.

\section{Results}

Membrane exposures were a complication during postoperative healing. Minor exposure of the coronal or interproximal portions of the ePTFE membranes occurred from weeks two to four in 11 cases. All of the exposures were treated according to the previously described protocol until membrane removal. No other healing problems or inflammatory reactions, such as allergic reactions, abscesses or infections were observed.

Table 1 presents clinical and radiographic data. The baseline clinical parameters were similar in both groups, with no significant differences. After 6 months, a statistically significant reduction in PPD $(p<0.001)$, rCAL gain $(p<0.001)$ and increase in $G R(p<0.001)$ were observed in both groups. The comparison of the changes in clinical measurements throughout the study revealed no significant differences between groups. Regarding the radiographic results, for comparisons between the groups at baseline, rCEJ-rBD and rCEJ-rAC demonstrated no statistically significant differences $(p=0.278$ and $p=0.599$, respectively). After 6 months, rCBR was detected for both groups $(-0.32 \pm 1.05 \mathrm{~mm}$ for GTR group and $-0.67 \pm 1.05 \mathrm{~mm}$ for $\mathrm{ABM} / \mathrm{P}-15)$. There was a significant $r B F(2.49 \mathrm{~mm})$ only for $A B M / P-15$ group. After 6 months, the GTR group presented a statistically significant higher rCEJ-rBD than the ABM/P-15 group.

The baseline defect areas were similar between groups, as well as the residual defects after 6 months (Table 2). There were statistically significant differences between baseline and residual defects after 6 months for both groups. The radiopaque areas, which revealed density gain in DSR, were statistically larger in ABM/P-15 group than in GTR group. These areas corresponded to $93.16 \%$ of the baseline defect in the ABM/P-15 and 62.03\% in the GTR group.

The radiographic density, verified by mean gray levels, is presented in Figure 3. The baseline density was $73.42 \pm 34.21$ for the ABM/P-15 group and $66.37 \pm 34.80$ for the GTR group, with no significant difference between them $(p=0.311)$. After 3 months, a density of $86.03 \pm 31.00$ and $70.58 \pm 36.74$ was found in the ABM/P-15 and the GTR groups, respectively, with no significant 
difference $(p=0.311)$. In the 6 -month radiographs there was a significant increase $(p<0.05$ for the ABM/P-15 group and $p<0.01$ for the GTR group) in density when compared with baseline densities, for both groups ( $91.47 \pm 32.38$ for the ABM/P15 and $75.64 \pm 36.35$ for the GTR group).

The cytokines quantification is summarized in Table 3. The statistical analysis demonstrated no significant difference in any of the evaluated parameters, in both inter or intra-groups comparisons.

\section{Discussion}

The clinical results of this study demonstrated that the use of $A B M / P-15$ and GTR in intrabony defects may lead to statistically significant PPD reduction and CAL gain for patients with G-AgP. Very few studies analyzed periodontal regenerative treatment in patients affected by G-AgP. Mengel et al. (14) evaluated the effectiveness of bioabsorbable membrane and bioactive glass (BA) in the treatment of intrabony defects in patients with G-AgP and presented, after 6 months, a PPD reduction of $4 \mathrm{~mm}$ and rCAL gain of $3.1 \mathrm{~mm}$ for the GTR group and PPD reduction of $3.8 \mathrm{~mm}$ and $\mathrm{rCAL}$ gain of $2.9 \mathrm{~mm}$ for

Table 2. Radiographic area measurements



Wilcoxon signed-rank test. *mean \pm sd. + Statistically significant difference $(p<0.05)$.
BA group. Zucchelli et al. (2) reported a rCAL gain of 6.1 $\mathrm{mm}$ and a PPD reduction of $7.1 \mathrm{~mm}$ in patients with $\mathrm{AgP}$ treated with GTR, after 12 months. These improvements are greater than the results observed in this study, but a comparatively higher preoperative PPD (8 $\mathrm{mm}$ to $9 \mathrm{~mm}$ ) was reported in the previous studies. It was shown that a greater amount of rCAL gain and PPD reduction can be expected in deeper defects.

Currently there are no studies comparing the outcomes of $A B M / P-15$ and GTR in the treatment of intrabony defects. In agreement with the results of the present study, Yukna et al. (8) observed a PPD reduction of $2.4 \mathrm{~mm}$ and rCAL gain of $1.3 \mathrm{~mm}$ in intrabony defects in patients with chronic periodontitis treated with ABM/P-15, after 6 to 7 months, while PPD reduction was of 2.1 and $1.5 \mathrm{~mm}$ for decalcified freeze-dried bovine allograft (DFDBA) group and open flap debridement group (DEBR), respectively; rCAL gain observed was $0.5 \mathrm{~mm}$ for DFDBA group and 0.1 $\mathrm{mm}$ for DEBR group. In other clinical studies that evaluated $A B M / P-15$ was also verified a PPD reduction, ranging from $2.98 \mathrm{~mm}$ to $4.19 \mathrm{~mm}$, and rCAL gain, from $2.2 \mathrm{~mm}$ to 2.89 $\mathrm{mm}(7,9,15)$. There were no statistically significant clinical differences between ABM/P-15 groups with the control groups in these studies [(DFDBA (8), open flap debridement $(8,9)$ or anorganic bone matrix (7)]. Previous studies have reported on the small increase in gingival recession and systematic reviews have shown that this is a fairly common finding after regenerative procedures (3).

As for the membrane exposures that occurred during the early healing period, it is important to highlight that many authors consider that this may impair periodontal regeneration due to local
Table 3. GCF cytokine concentrations

\begin{tabular}{|c|c|c|c|c|}
\hline $\begin{array}{l}\text { [ ] cytokine } \\
\text { (pg/ } / \mu \mathrm{L})^{*}\end{array}$ & Baseline & 3 months & 6 months & $\begin{array}{c}\mathrm{p} \\
\text { value }^{+}\end{array}$ \\
\hline \multicolumn{5}{|l|}{$1 \mathrm{~L}-1 \beta$} \\
\hline ABM/P-15 & $4.94 \pm 1.09$ & $7.25 \pm 2.12$ & $8.60 \pm 3.03$ & 0.210 \\
\hline GTR & $6.26 \pm 1.77$ & $8.51 \pm 2.59$ & $10.05 \pm 3.38$ & 0.927 \\
\hline$p$ value ${ }^{\ddagger}$ & 0.311 & 0.753 & 0.600 & \\
\hline \multicolumn{5}{|l|}{ lL-6 } \\
\hline ABM/P-15 & $0.34 \pm 0.16$ & $0.63 \pm 0.24$ & $0.67 \pm 0.19$ & 0.436 \\
\hline GTR & $0.26 \pm 0.08$ & $0.41 \pm 0.17$ & $0.52 \pm 0.13$ & 0.338 \\
\hline$p$ value ${ }^{*}$ & 0.610 & 0.695 & 0.844 & \\
\hline
\end{tabular}

Friedman test. * mean \pm sd.

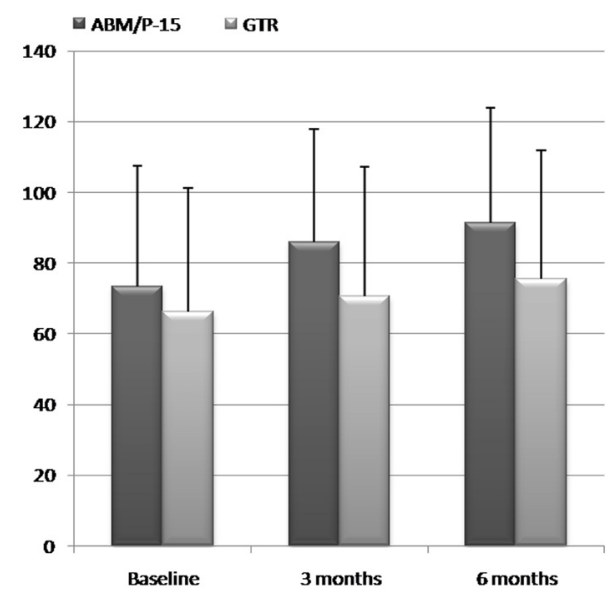

Figure 3. Radiographic density (mean gray levels \pm sd). 
bacterial contamination. However, in a meta-analysis review was observed a small negative effect of membrane exposure on GTR procedures. The membrane barriers used for GTR are never sealed off from the oral fluids and, therefore, from the oral microflora via the pseudo-sulcus at the membrane-gingival interface. Consequently, there is only a small difference regarding the bacterial load in membrane barriers that become exposed (16). Moreover, as described previously, antibiotics, chlorhexidine digluconate solution and weekly prophylaxis were used in order to avoid a significant bacterial infection.

In the radiographic analysis, a statistically significant reduction of the rCEJ-rBD was observed only for ABM/P-15 group, with an rBF of $2.49 \mathrm{~mm}$, corroborating the studies of Yukna et al. (8), who verified a bone fill of $2.8 \mathrm{~mm}$ and $2.9 \mathrm{~mm}$ (7) in re-entry surgeries after treatment with $A B M / P-15$. This $r B F$ was significantly higher than the one observed in GTR group. For the defects treated with the GTR, there was an rBF of $0.73 \mathrm{~mm}$, similar to that of Mayfield et al. (17) $(0.6 \mathrm{~mm})$ and Eickholz et al. (18) $(0.7 \mathrm{~mm})$, but lower than the rBF observed in other studies $(19,20)$. The radiographic crestal bone resorptions ( $r \mathrm{CBR}$ ) observed in both groups are consistent with previous studies, which showed some amount of $\mathrm{rCBR}$ for defects treated with ABM/P-15 $(7,8)$ and GTR $(18-20)$. Both groups presented a progressive gain in radiographic density when the mean gray level was compared between baseline, 3- and 6-month radiographs. The statistical analysis revealed that the mean gray level observed in the 6-month radiographs was statistically higher than in baseline radiographs of both groups. This gain in mean gray levels level in periodontal defects treated with regenerative procedures has already been demonstrated (21). It was observed that in 93.16\% of the baseline defects in the ABM/P-15 group there was gain in radiographic density, while in the GTR group this improvement was observed in $62.03 \%$ of the defects. In previous studies, the radiographic recorded area of bone density gain was around 55\% of the initial defect after GTR procedures (22), while it was about $80 \%$ in defects treated with tricalciumphosphate (21). The radiographic outcomes of this study apparently demonstrate that the $A B M / P-15$ group presented superiority in radiographic fill of the defects, with higher radiographic density. This may possibly be due to its potential of enhancing bone regeneration required for restoration of the periodontal attachment apparatus. However, it should be noted that since the resorption rate of the bovine bone mineral is very slow, this bone fill of the defect consisted of a combination of bovine bone particles and regenerating vital human bone and the defect fill by the radiopaque granules and true periodontal regeneration cannot be distinguished. A recent study detected $36.7 \pm 1.6 \%$ of residual particles of $A B M / P-15$ after sinus augmentation in humans after 6 months (23). Moreover, in GTR group, the translucent areas representing bony defects can show discrete signs of what would constitute partial fill of new bone. Therefore, a longer healing period can be required for a more definitive radiographic evidence of bone maturation or for true bone regeneration to become visible.

The present results showed no statistically significant differences between cytokine concentrations (IL-1 $\beta$ and IL6) found at baseline, 3- and 6-month evaluations. However, a tendency to increase in both cytokine concentrations was observed. Since they are pro-inflammatory, this finding could be considered controversial. Nevertheless, many studies showed that pro-inflammatory cytokines are present in healthy sites $(12,13,24)$. Moreover, IL-1 and IL-6 genes were detected in tissues and cells from sites treated with periodontal regenerative procedures. Furthermore, it should be considered that the baseline examination was performed immediately after an extensive nonsurgical and surgical periodontal treatment. The initial concentrations found in the present study were lower than those reported in the literature for healthy sites [10.23 pg/ $/ \mu \mathrm{L}$ (24) to $18.1 \mathrm{pg} / \mu \mathrm{L}(25)]$, in studies where periodontal treatments were not previously performed. Thus, it is possible that the periodontal therapy initially performed in this study could have led to very low levels of cytokine. The concentrations found after 6 months are still in accordance with periodontal health. It should also be addressed that systemic administration of antibiotics may possibly have an effect on GCF cytokine expression. Since the use of antibiotics in patients with aggressive periodontitis and after regenerative procedures is supported by literature, they were prescribed to patients with the aim to provide all clinical benefits that could be obtained from periodontal treatment. Moreover, this was a split-mouth study and therefore the effects of antibiotics were equal for both evaluated sites, allowing comparisons between them.

This study showed that both treatments (ABM/P-15 and GTR) provided significant improvements in clinical parameters for intrabony periodontal defects in patients with generalized aggressive periodontitis in a 6-month postoperative period. There were no differences in clinical parameters and cytokine quantification between the groups. ABM/P-15 group presented superior results regarding radiographic bone fill than GTR group, but this improvement can be attributed to the presence of bone graft granules. Longer follow-up periods and analysis of other cytokines involved in inflammation and tissue repair may elucidate other processes, which could help understanding the prognosis and success of regenerative treatments of patients with AgP. 


\section{Resumo}

Defeitos periodontais infra-ósseos representam um desafio particular no tratamento, especialmente em pacientes com periodontite agressiva generalizada $(\mathrm{PAg}-\mathrm{G})$. Procedimentos regenerativos tem sido indicados para esta situação clínica. 0 objetivo deste estudo foi comparar os resultados do tratamento de defeitos periodontais infra-ósseos com associação de matriz óssea inorgânica bovina com o P-15 (MOI/P-15) ou regeneração tecidual guiada (RTG) em pacientes com PAg-G. 15 pacientes com $\mathrm{PAg}-\mathrm{G}$, com pelo menos dois defeitos periodontais infra-ósseos (profundidade de sondagem $\geq 4 \mathrm{~mm}$ e componente infraósseo $\geq 3 \mathrm{~mm}$ ) foram selecionados. Os pacientes foram aleatoriamente alocados para serem tratados com MOI/P-15 ou RTG. No exame inicial, e aos 3 e 6 meses após a cirurgia, os parâmetros clínicos e radiográficos e as concentrações de IL-1 $\beta$ e IL-6 no fluido gengival foram registrados. Houve uma redução significativa profundidade de sondagem $(p<0,001)$ para ambos os grupos $(2,27 \pm 0,96 \mathrm{~mm}$ para o grupo MOI/P-15 e 2,57 \pm $1,06 \mathrm{~mm}$ para o grupo RTG). Um ganho no nivel clínico de inserção $(1,87$ $\pm 0,94 \mathrm{~mm}$ para o grupo MOI/P-15 e 2,09 $\pm 0,88 \mathrm{~mm}$ para o grupo RTG) também foi observado. Na comparação entre grupos, não houve diferenças estatisticamente significativas nos parâmetros clínicos. 0 preenchimento ósseo radiográfico foi mais expressivo no grupo MOI/P-15 $(2,49 \mathrm{~mm}) \mathrm{do}$ que no grupo RTG $(0,73 \mathrm{~mm})$. Na análise radiográfica, as radiografias de subtração apresentaram ganho médio de área radiopaca em relação ao defeito inicial de $93,16 \%$ para grupo $\mathrm{MOI} / \mathrm{P}-15$, contra $62,03 \%$ para o grupo RTG. Na análise das citocinas, não foram observadas diferenças estatisticamente significantes nas comparações intra e entre os grupos. 0 tratamento de defeitos infra-ósseos com MOI/P-15 ou RTG em pacientes com $\mathrm{PAg}-\mathrm{G}$, em um periodo de 6 meses, levou a melhoras nos parâmetros clínicos. 0 uso de MOI/P-15 levou a um maior preenchimento radiográfico.

\section{¿ Acknowledgments}

This study was supported by São Paulo State Research Foundation (FAPESP Grant 2006/04404-5), SP, Brazil. The authors report no conflicts of interest.

\section{References}

1. Rapp GE, Pineda-Tujillo N, McQuillin A, Tonetti M. Genetic power of a Brazilian three-generation family with generalized aggressive periodontitis. Braz Dent J 2010;21:137-141.

2. Zucchelli G, Bernardi F, Montebugnoli L, De SM. Enamel matrix proteins and guided tissue regeneration with titanium-reinforced expanded polytetrafluoroethylene membranes in the treatment of infrabony defects: a comparative controlled clinical trial. J Periodontol 2002;73:312.

3. Murphy KG, Gunsolley JC. Guided tissue regeneration for the treatment of periodontal intrabony and furcation defects. A systematic review. Ann Periodontol 2003;8:266-302.

4. Ribeiro FV, Nociti Júnior FH, Sallum EA, Sallum AW, Casati MZ. Use of enamel matrix protein derivative with minimally invasive surgical approach in intra-bony periodontal defects: clinical and patientcentered outcomes. Braz Dent J 2010;21:60-67.

5. Nyman S, Lindhe J, Karring T, Rylander H. New attachment following surgical treatment of human periodontal disease. J Clin Periodontol 1982;9:290-296

6. Qian JJ, Bhatnagar RS. Enhanced cell attachment to anorganic bone mineral in the presence of a synthetic peptide related to collagen. J Biomed Mater Res 1996;31:545-554.

7. Yukna RA, Krauser JT, Callan DP, Evans GH, Cruz R, Martin M. Multicenter clinical comparison of combination anorganic bovine-derived hydroxyapatite matrix (ABM)/cell binding peptide (P-15) and $A B M$ in human periodontal osseous defects. 6-month results. J Periodontol 2000;71:1671-1679.

8. Yukna RA, Callan DP, Krauser JT, Evans GH, Aichelmann-Reidy ME, Moore $K$, et al.. Multi-center clinical evaluation of combination anorganic bovine-derived hydroxyapatite matrix (ABM)/cell binding peptide (P15 ) as a bone replacement graft material in human periodontal osseous defects. 6-month results. J Periodontol 1998;69:655-663.
9. Bhongade ML, Tiwari IR. A comparative evaluation of the effectiveness of an anorganic bone matrix/cell binding peptide with an open flap debridement in human infrabony defects: a clinical and radiographic study. J Contemp Dent Pract 2007:8:25-34.

10. Fernandes $P G$, Novaes Jr. $A B$, Queiroz AC, Souza SLS, Taba Jr. M, Palioto DB, et al.. Ridge preservation with acellular dermal matrix and anorganic bone matrix cell-binding peptide $\mathrm{P}-15$ after tooth extraction in humans. J Periodontol 2011;82:72-79.

11. Nazareth CA, Cury PR. Use of anorganic bovine-derived hydroxyapatite matrix/cell-binding peptide (P-15) in the treatment isolated class I gingival recession of defects: a pilot study. J Periodontol 2011;82:700707.

12. Kamma JJ, Giannopoulou C, Vasdekis VG, Mombelli A. Cytokine profile in gingival crevicular fluid of aggressive periodontitis: influence of smoking and stress. J Clin Periodontol 2004;31:894-902.

13. Toker H, Poyraz O, Eren K. Effect of periodontal treatment on IL-1 beta, IL-1ra, and IL-10 levels in gingival crevicular fluid in patients with aggressive periodontitis. J Clin Periodontol 2008;35:507-13.

14. Mengel R, Soffner M, Flores-de-Jacoby L. Bioabsorbable membrane and bioactive glass in the treatment of intrabony defects in patients with generalized aggressive periodontitis: results of a 12-month clinical and radiological study. J Periodontol 2003;74:899-908.

15. Matos SM, Guerra FA, Krauser J, Marques F, Ermida JM, Sanz M. Clinical evaluation of the combination of anorganic bovine-derived hydroxyapatite matrix/cell-binding peptide $(\mathrm{P}-15)$ in particulate and hydrogel form as a bone replacement graft material in human periodontal osseous defects: 6 -month reentry controlled clinical study. J Periodontol 2007;78:1855-1863.

16. Machtei EE. The effect of membrane exposure on the outcome of regenerative procedures in humans: a meta-analysis. J Periodontol 2001;72:512-516.

17. Mayfield L, Soderholm G, Hallstrom H, Kullendorff B, Edwardsson S,

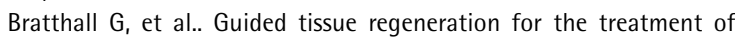
intraosseous defects using a bioabsorbable membrane. A controlled clinical study. J Clin Periodontol 1998;25:585-595.

18. Eickholz $\mathrm{P}$, Horr $T$, Klein $F$, Hassfeld $S$, Kim TS. Radiographic parameters for prognosis of periodontal healing of infrabony defects: two different definitions of defect depth. J Periodontol 2004;75:399-407.

19. Eickholz P, Kim TS, Holle R. Regenerative periodontal surgery with nonresorbable and biodegradable barriers: results after 24 months. J Clin Periodontol 1998;25:666-676.

20. Walters SP, Greenwell H, Hill M, Drisko C, Pickman K, Scheetz JP. Comparison of porous and non-porous teflon membranes plus a xenograft in the treatment of vertical osseous defects: a clinical reentry study. J Periodontol 2003;74:1161-1168.

21. Christgau M, Moder D, Wagner J, Glassl M, Hiller KA, Wenzel A, et al. Influence of autologous platelet concentrate on healing in intra-bony defects following guided tissue regeneration therapy: a randomized prospective clinical split-mouth study. J Clin Periodontol 2006;33:908921.

22. Christgau M, Bader N, Schmalz G, Hiller KA, Wenzel A. GTR therapy of intrabony defects using 2 different bioresorbable membranes: 12-month results. J Clin Periodontol 1998;25:499-509.

23. Pettinicchio M, Traini T, Murmura G, Caputi S, Degidi M, Mangano C, et al.. Histologic and histomorphometric results of three bone graft substitutes after sinus augmentation in humans. Clin Oral Invest 2012;16:45-53.

24. Yucel 00, Berker E, Gariboglu S, Otlu H. Interleukin-11, interleukin1 beta, interleukin-12 and the pathogenesis of inflammatory periodontal diseases. J Clin Periodontol 2008;35:365-370.

25. Engebretson SP, Grbic JT, Singer R, Lamster IB. GCF IL-1beta profiles in periodontal disease. J Clin Periodontol 2002;29:48-53.

Received January 24, 20113 Accepted May 17, 2013 